\title{
THE INTERACTION DURING RECOMBINATION BETWEEN CLOSELY LINKED ALLELIC FRAMESHIFT MUTANT SITES IN ASCOBOLUS IMMERSUS
}

\author{
I. A (OR B) AND C TYPE MUTANT SITES \\ J.-L. ROSSIGNOL AND V. HAEDENS \\ Laboratoire de Génétique Bât. 400, Université de Paris-Sud, 91405 Orsay-Cedex, France
}

Received 16.ix.77

\section{Summary}

Five two-point crosses involving two closely linked allelic mutations, one of which gives postmeiotic segregations, are analysed. A quantitative analysis of the origin of the simplest events is performed within the framework of a hypothesis of hybrid DNA formation spanning both sites, followed by excision repair. The results are consistent with the frequent involvement of two homologous chromatids in hybrid DNA and with the occurrence of recombination primarily by termination of excision repair between the two sites rather than by termination of the hybrid DNA between them.

\section{INTRODUCTION}

SEveral classes of $A$. immersus mutants have been defined based on their conversion spectrum (Leblon, 1972a). Some mutants give only $6: 2$ (e.g. $2+6 \mathrm{~m}$ and $6+2 \mathrm{~m}$ asci). These mutants usually show a disparity in the direction of conversion: type A mutants yield an excess of conversions to wild-type $(6+2 \mathrm{~m}$ asci), whereas type $B$ mutants yield a converse excess to mutant $(2+6 \mathrm{~m}$ asci). Other mutants (type $\mathrm{G}$ ) exhibit numerous postmeiotic segregations (PMS) besides $6: 2$ asci; the PMS correspond to $5: 3$ (e.g. $3+5 \mathrm{~m}$ and $5+3 \mathrm{~m}$ asci) and to aberrant $4: 4$ asci that are also usually found whenever they can be detected (Paquette, 1978).

A and B type mutants are frameshift mutants corresponding to small additions or deletions of nucleotides (Leblon, 1972b, 1974; Leblon and Paquette, 1978). These mutants are believed to induce correction when the mutation is in hybrid DNA (HDNA) during recombination events occurring in meiosis. Correction would also be responsible for the disparity in conversion; it would initiate preferentially on the wild-type strand (for B type mutants) or on the mutant strand (for A type mutants) (Leblon and Rossignol, 1973).

In a cross of double mutant to wild-type, involving two closely linked $B$ and C allelic mutant sites, Leblon and Rossignol (1973) found a drastic change in the conversion spectrum of the $\mathrm{C}$ mutant, compared to a $\mathrm{C}$ mutant $\times$ wild-type control cross. The frequency of $5: 3$ asci were strongly depressed, with a parallel enhancement of the $6: 2$ type. A strong disparity in the direction of conversion appeared, whereas parity was observed in the control cross. These changes were confined to conversions simultaneously involving both the $B$ and $C$ sites on the same chromatid. The results suggested that the correction induced on the $\mathrm{B}$ site frequently over- 
lapped the $\mathrm{G}$ site, when both were involved in HDNA. Hence, the B site imposed its own conversion spectrum on the $\mathrm{C}$ site. Furthermore, among the asci showing a $6: 2$ segregation for the $B$ site, the relative frequency of those giving a $6: 2$, a $5: 3$ and an aberrant $4: 4$ for the $C$ site were shown to be in good agreement with the hypothesis that two homologous chromatids are most frequently composed of HDNA formed during genetic recombination.

Five similar crosses involving both a type $\mathrm{C}$ and a type $\mathrm{A}$ or $\mathrm{B}$ with closely linked mutant sites were performed. The analysis of these crosses is presented.

\section{Material AND Methods}

\section{(i) Ascospore pigmentation mutants}

The crosses involved six distinct mutant sites of the $b 2$ pigmentation locus. These mutants belong to one cluster of intragenic suppression (Leblon and Paquette, 1978) and are called b2A0, b2Al, b2A2, b2A3, b2A4, b2A6. They will be designed: $0,1,2,3,4,6$, respectively. Each one of these mutations alone leads to a white spore phenotype and corresponds to a frameshift mutation (Leblon, 1972b, 1974, manuscript in preparation). The sequence of these mutant sites was determined by twopoint crosses (Leblon and Paquette, 1978) and confirmed in three-point crosses (Leblon, manuscript in preparation). This sequence and the sign of the phase shift of each mutant are:

$\begin{array}{cccccc}4 & 2 & 3 & 1 & 0 & 6 \\ - & - & - & - & + & +\end{array}$

The mutants 1, 2, 3, 6 give a type A conversion spectrum. They will be called $\mathrm{A}$ mutants. The mutant 0 gives a type $\mathrm{B}$ and 4 gives a type $\mathrm{C}$ conversion spectrum. They will be called $\mathrm{B}$ and $\mathrm{C}$ mutants, respectively. Leblon (1972b) demonstrated that in Ascobolus, frameshift mutants usually give an $\mathrm{A}$ or $\mathrm{B}$ type conversion spectrum; obviously 4 constitutes an exception to this behaviour, since it gives a $\mathrm{C}$ type conversion spectrum. Five double mutants of opposite phase, with a coloured ascospore phenotype were used: 1-0, 3-0, 2-0 (brown spores), 4-0 and 4-6 (pink spores).

\section{(ii) Crosses}

The crosses investigated are indicated in table 1. Each cross is heterozygous for only two sites: the G site (4) and either one A site (crosses I, II, III, V) or one B site (cross IV). In each cross, the two parental spore phenotypes corresponded to pink and brown pigmentation, clearly distinguishable from each other, and from the two white recombinant phenotypes. Hence, all the conversions to wild-type or to mutant involving either one or both sites could easily be screened as asci other than 4 brown : 4 pink.

All the crosses were heterozygous for an ascospore shape gene which is independent of $b 2$. The $r n d 1$ spores are round whereas $m d 1^{+}$are oval. The conversion frequency of this marker being very low (Paquette, 1978), nearly all the asci exhibit a $4: 4$ segregation of shape. This marker has a double convenience: accidental false octads can be detected when they 
TABLE 1

Parental and recombinant genotypes and phenotypes

\begin{tabular}{|c|c|c|c|c|c|c|}
\hline \multirow[b]{2}{*}{$\begin{array}{c}\text { Cross } \\
\text { number }\end{array}$} & & & \multicolumn{2}{|c|}{ Parental phenotype } & \multirow{2}{*}{$\begin{array}{l}\text { Recombinant } \\
\text { genotype } \\
\text { (b2 gene) }\end{array}$} & \multirow{2}{*}{$\begin{array}{l}\text { Recombinant } \\
\text { phenotype } \\
\text { (spore colour) }\end{array}$} \\
\hline & Parental ge & enotype & $\begin{array}{l}\text { Spore } \\
\text { colour }\end{array}$ & $\begin{array}{l}\text { Spore } \\
\text { shape }\end{array}$ & & \\
\hline I & $\frac{+20}{4+0}$ & $\frac{+}{m n d 1}$ & $\begin{array}{l}\text { Brown } \\
\text { Pink }\end{array}$ & $\begin{array}{l}\text { Oval } \\
\text { Round }\end{array}$ & $\begin{array}{l}4-2-0 \\
0\end{array}$ & $\begin{array}{l}\text { White } \\
\text { White }\end{array}$ \\
\hline II & $\frac{+30}{4+0}$ & $\frac{+}{m d 1}$ & $\begin{array}{l}\text { Brown } \\
\text { Pink }\end{array}$ & $\begin{array}{l}\text { Oval } \\
\text { Round }\end{array}$ & $\begin{array}{l}4-3-0 \\
0\end{array}$ & $\begin{array}{l}\text { White } \\
\text { White }\end{array}$ \\
\hline III & $\frac{+10}{4+0}$ & $\frac{+}{m d 1}$ & $\begin{array}{l}\text { Brown } \\
\text { Pink }\end{array}$ & $\begin{array}{l}\text { Oval } \\
\text { Round }\end{array}$ & $\begin{array}{l}4-1-0 \\
0\end{array}$ & $\begin{array}{l}\text { White } \\
\text { White }\end{array}$ \\
\hline IV & $\frac{+\quad t}{40}$ & $\frac{+}{\text { rndl }}$ & $\begin{array}{l}\text { Dark brown } \\
\text { Pink }\end{array}$ & $\begin{array}{l}\text { Oval } \\
\text { Round }\end{array}$ & $\begin{array}{l}4 \\
0\end{array}$ & $\begin{array}{l}\text { White } \\
\text { White }\end{array}$ \\
\hline V & $\frac{t+}{46}$ & $\frac{r n d 1}{t}$ & $\begin{array}{l}\text { Dark brown } \\
\text { Pink }\end{array}$ & $\begin{array}{l}\text { Round } \\
\text { Oval }\end{array}$ & $\begin{array}{l}4 \\
6\end{array}$ & $\begin{array}{l}\text { White } \\
\text { White }\end{array}$ \\
\hline
\end{tabular}

lead to a non-4 : 4 segregation of shape, and aberrant $4: 4$ segregations at the $b 2$ locus can be detected phenotypically in two-thirds of the cases by the odd segregation for ascospore shape and colour (Paquette, 1978). In the crosses studied, the number of such events may be estimated directly.

\section{(iii) Culture media and crossing techniques}

The details of media and culture techniques have been previously described (Rizet et al., 1960; Lissouba et al., 1962; Yu Sun, 1964).

All crosses were performed at $22^{\circ} \mathrm{C}$ until the cultures were mature. They were then transferred to $11^{\circ} \mathrm{C}$ and the asci were harvested on an agar screen between the 2 nd and the 6 th day. Low temperature enhances pigmentation: whereas the distinction between light pigmented and white spores is sometimes difficult at room temperature, it becomes easy at $11^{\circ} \mathrm{C}$. Furthermore, the dispersion of spores (obtention of asci with less than eight ascospores) is reduced at low temperature; thus the occurrence of false octads was almost completely eliminated in these crosses.

\section{Results}

(i) The types of asci found and their significance

The number of asci of each type obtained in the progeny of crosses $\mathbf{I}$ to $\mathrm{V}$ is indicated in table 2. Twenty-three distinct ascus phenotypes were observed:

\section{(a) Simple conversion events}

Ascus types $a$ to $m$ correspond to conversion events involving no more than two homologous chromatids. The genotypes of these asci are indicated in fig. 1. The assignment of a genotype from the phenotype of the asci is based on the following assumption: where there is a formal choice between PMS at A (or B) and none at $\mathrm{C}$ and PMS at $\mathrm{C}$ and none at $\mathrm{A}$ (or B), the 


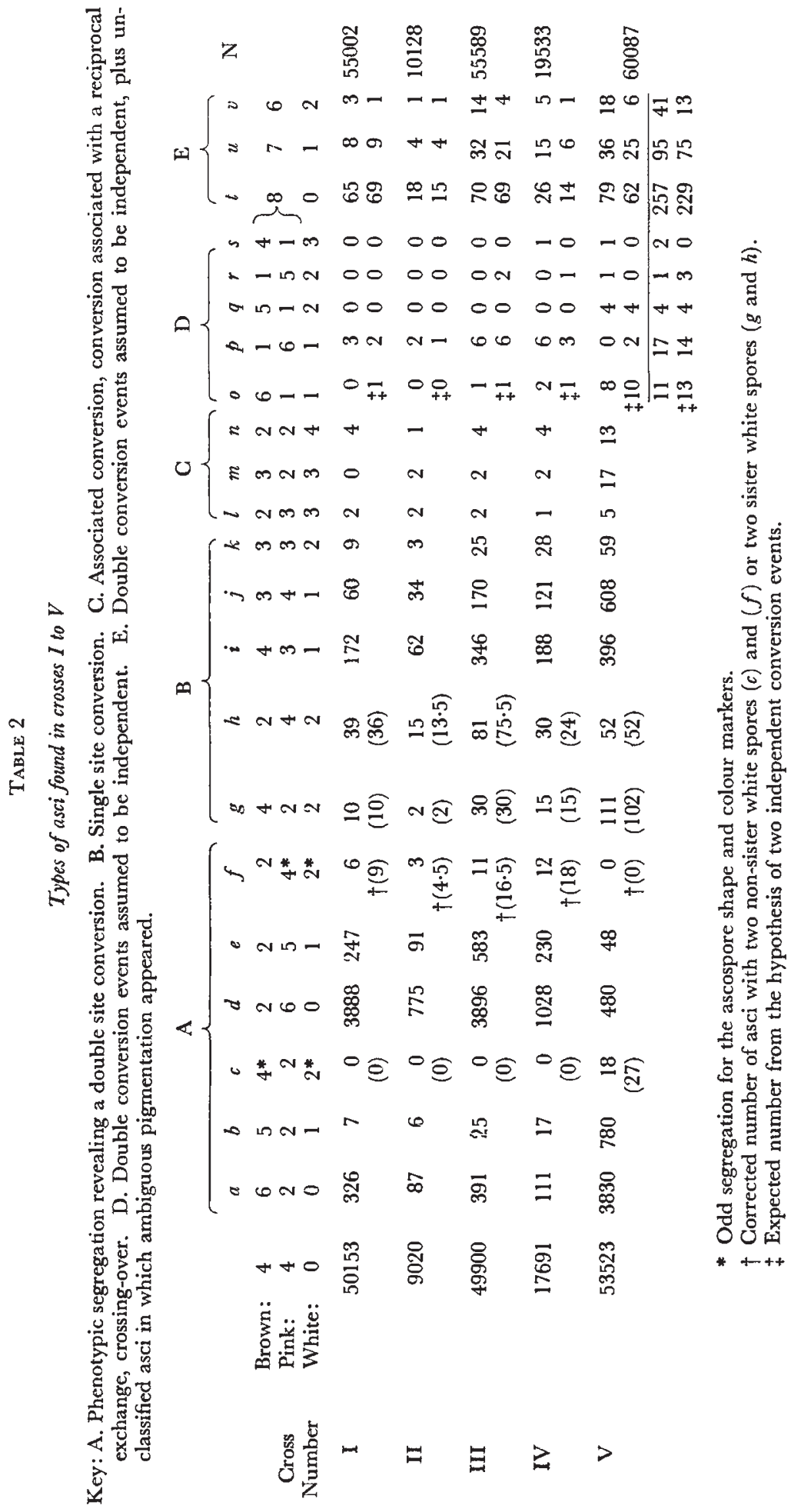


second option is always correct. The main evidence for this assumption comes from the analysis by Leblon and Rossignol (1973) of asci issued from a cross identical to cross IV and corresponding to classes where the alternative for PMS arose: all the 39 asci with confirmed conversion events arose from a PMS at $\mathrm{C}$ and none at $\mathrm{B}$. Three classes may be distinguished in

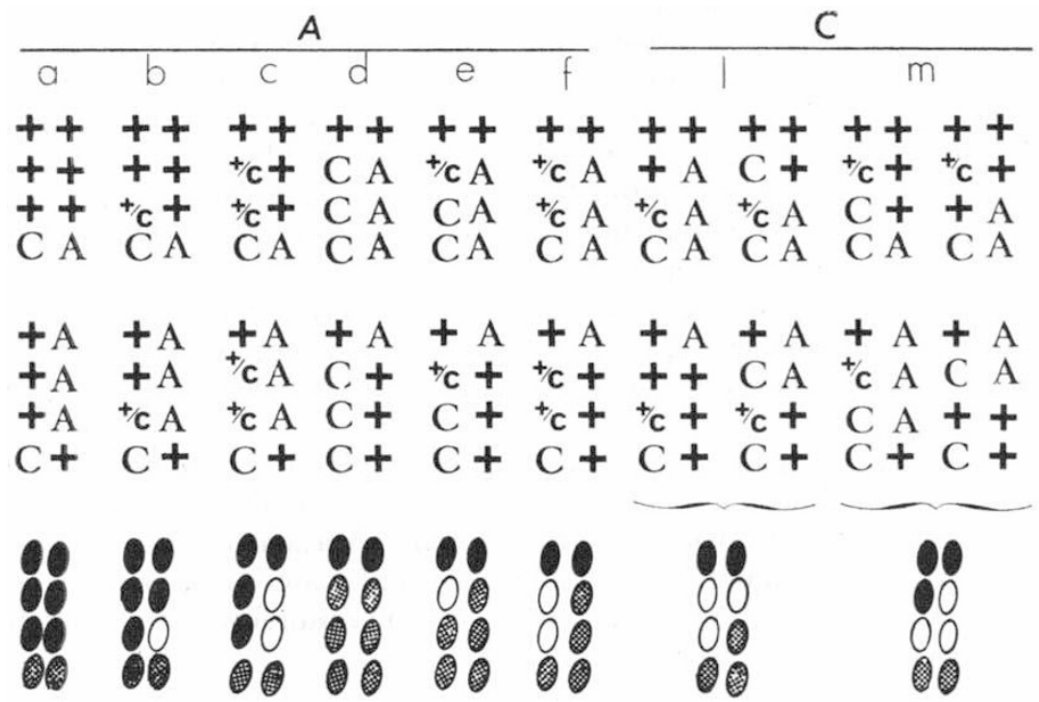

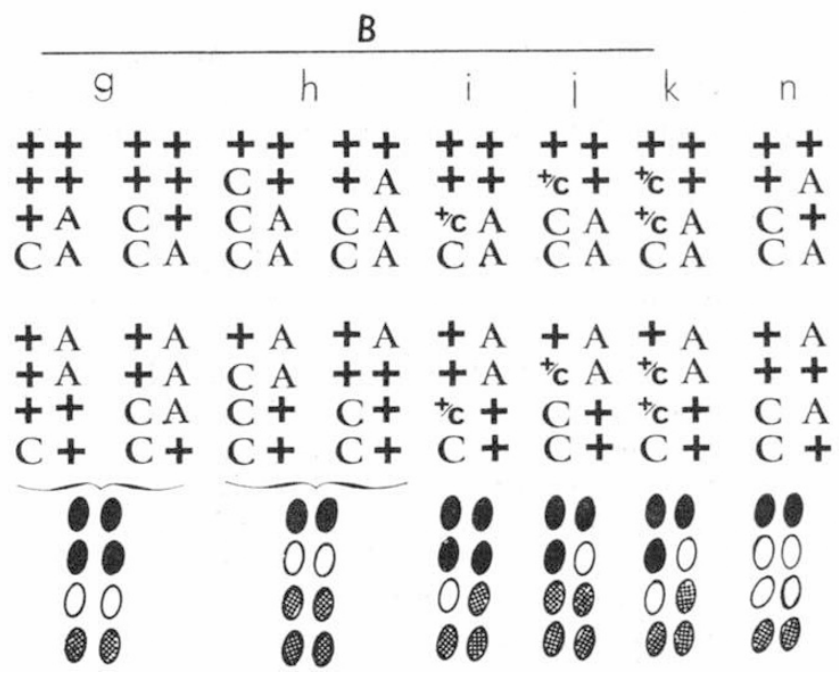

FiG. 1.-Correspondence between genotype and phenotype in 14 types of asci resulting from simple conversion events or crossing-over. Each line corresponds to the genotype of a pair of ascospores issued from one meiotic product. Postmeiotic segregation at site $\mathbf{C}$ is indicated: $+/ \mathrm{c}$ for the corresponding pair of ascospores. Upper ascus genotype: crosses IV and V. In cross V, A corresponds to 6, in cross IV, A should be replaced by $\mathrm{B}(0)$. Lower ascus genotype: crosses I to III. A corresponds either to 1, 2 or 3; the mutant site 0 is present in both parents: it is not indicated. $A$ : Double site conversion. $B$ : Single site conversion. $C$ : Associated conversion, or PMS for site $\mathrm{C}$ associated with a reciprocal exchange between $A$ and $C$. 
fig. 1: type $a$ to $f$ result from a double site conversion where the same chromatid is involved in conversion for both mutations; types $g$ to $k$ result from a single site conversion; types $l$ and $m$ result either from a conversion occurring at each of the two sites and involving two distinct chromatids (associated conversions), or from a $5: 3$ for the $\mathrm{C}$ site associated with a reciprocal exchange between the $\mathrm{C}$ and the $\mathrm{A}$ (or $\mathrm{B}$ ) site.

Types $c$ and $g$ on the one hand and types $f$ and $h$ on the other hand, show the same ascospore colour phenotype. The two white spores, however, correspond to distinct pairs (they arise from distinct meiotic products) in $c$ and $f$, whereas they correspond to the same pair in $g$ and $h$ asci. In the latter case, the two white spores should always exhibit the same shape, whereas in two-thirds of the $c$ and $f$ asci, they should exhibit different shapes (one round and one oval). Hence, an estimation of the actual number of $c, g, f$ and $h$ asci may be made. The numbers given in table 2 for $c$ and $f$ are those of asci with differently shaped white spores; the numbers given for $g$ and $h$ are those of asci with identically shaped white spores. Corrected numbers for $c, g, f$ and $h$ asci are indicated between parentheses.

This means of identification results in no ambiguity in the determination of the genotype from the phenotype of asci $a$ to $f$ (double site conversions). Among single site conversions, the PMS should always involve site $\mathrm{C}$, making the $i, j$ and $k$ asci unambiguous; only the $g$ and $h$ asci must be analysed in order to determine their genotype, since they can result from a $6: 2$ involving either the $\mathrm{C}$ or the $\mathrm{A}$ (or B) site.

\section{(b) Crossing-over}

Ascus type $n$ is expected from a cross-over. Among five asci analysed (from crosses I, III and V), however, all corresponded to a new mutation to a white spored phenotype in a pigmentation locus independent of $b 2$.

\section{(c) Complex conversion events}

Asci $o$ to $s$ can only be explained if two independent conversion events occurred, involving two sister chromatids (i.e. type $o$ must result from a double site conversion event leading to an $a$ type ascus, plus a single site conversion for the $\mathrm{C}$ site, leading to an $i$ type ascus). The expected numbers of asci of these types, assuming two independent events, are indicated in table 2: a good fit is found between observed and expected values. This agrees with previous observations (Leblon, 1972a).

Asci $t$ to $v$ showed no significant difference in the intensity of spore pigmentation. The asci could result either from independent conversion events involving two sister chromatids and leading to coloured ascospores all having the same genotype, or from some phenotype ambiguity such that the two parental genotypes are indistinguishable. The numbers of such asci expected from the first assumption are indicated in table 2. The fit is rather good for $t$ and $u$ asci, but a significant excess of $v$ asci is observed when the results of all crosses are summed: a small number of $v$ asci may thus belong to one of the other ascus types with two white spores $(c, f, g$, $h, k, q$ or $r$ ). Although significant, this number is very small in relation to the overall results.

In the analysis of the results ascus types $n$ to $v$ will be grouped, since $n$ 
asci seem to correspond to new mutations and most of the 0 to $v$ asci result from the simultaneous occurrence of two independent events.

\section{(ii) Determination of the genotypes of ambiguous ascus categories}

Among the $a$ to $k$ types of asci, the genotype is directly inferred from the phenotype, except for the $g$ and $h$ asci (fig. 1). A sample of these two types of asci has been analysed from crosses I, III and V. In order to check the supposed genotypes of the $c$ and $f$ asci, certain of them have also been analysed. The results are indicated in table 3 , with an estimation of the number of asci with distinct genotypes leading to asci $c, f, g$ and $h$ for each cross.

TABLE 3

Analysis of $\mathrm{c}, \mathrm{f}, \mathrm{g}$ and $\mathrm{h}$ asci in crosses $I, I I I$ and $V$

Number of asci observed

Number of asci estimated

Number of asci analysed

Number of genotypes confirmed $\dagger$

Genotype of the
white spore $\left\{\begin{array}{cccc}0 & 5 & 0 & 5 \\ 4-x * *_{-} 0 & 0 & 1 & 1\end{array}\right.$

\begin{tabular}{|c|c|c|c|c|c|}
\hline \multicolumn{3}{|c|}{ Cross III } & \multicolumn{3}{|c|}{ Cross V } \\
\hline$f$ & $g$ & $h$ & $c$ & $g$ & $h$ \\
\hline 11 & 30 & 81 & 18 & 111 & 52 \\
\hline $16 \cdot 5$ & 30 & $75 \cdot 5$ & 27 & 102 & 52 \\
\hline 6 & 3 & 13 & 4 & 9 & 8 \\
\hline 6 & 3 & 12 & 4 & 8 & 7 \\
\hline 6 & 1 & 9 & 4 & 8 & 5 \\
\hline 0 & 2 & 3 & 0 & 0 & 2 \\
\hline
\end{tabular}

\section{Segregation}

for the site

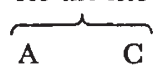

Corrected
number
of
asci $\begin{cases}2 / 6 & 4 / 4 \\ 2 / 6 & 4 / 4 \\ 6 / 2 & 4 / 4 \\ 4 / 4 & 2 / 6 \\ 4 / 4 & 6 / 2\end{cases}$

\begin{tabular}{|c|c|c|}
\hline \multicolumn{3}{|c|}{ Cross I } \\
\hline$f$ & $g$ & \\
\hline 6 & 10 & 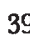 \\
\hline 9 & 10 & 3 \\
\hline 5 & 1 & \\
\hline 5 & 1 & \\
\hline 5 & & \\
\hline 0 & 1 & \\
\hline
\end{tabular}

$16 \cdot 5$
57
20
10
19

27

91

13

0

32

* Aberrant $4: 4$. * $x$ means 2 in cross $I$ and 1 in cross III.

$\dagger$ The genotype of the strains with coloured spores was confirmed by crossing with wildtype.

\$ The genotype of the recombinant strains with white spores was determined by crossing with wild-type and with 4.

(iii) Basic conversion spectrum

The conversion patterns of the mutants involved in each cross can be reconstituted from the results in tables 2 and 3 and are indicated in table 4 .

$A$ and $B$ sites + For $\mathrm{A}$ and $\mathrm{B}$ sites, the basic frequencies of conversion (BFG) range between 7 and $9 \times 10^{-2}$. In this part of the $b 2$ locus, most of the values observed for $A$ and $B$ mutants in single point crosses range from 8 to $16 \times 10^{-2}$ (Leblon, 1972b; Leblon, 1974; Rossignol and Paquette, manuscript in preparation). It is thus difficult to know if the values observed here correspond to a real decrease in the BFC.

The disparity values (DV in table 4 ) range from 8 to 12 , in good agreement with the results from single-point crosses (loc. cit.). Hence, little or no change can be detected in the conversion spectrum of the $\mathrm{A}$ and $\mathrm{B}$ sites in two-point crosses involving a second closely linked $\mathrm{G}$ site. 
The $C$ site $_{+}$The BFC range from 8 to $11 \times 10^{-2}$ for site 4 . The control cross gives a $\mathrm{BFC}$ value of $19 \times 10^{-2}$. Other single-point crosses involving site 4 , and taking in account aberrant $4: 4$ asci, give $B F C$ values ranging from 10 to 19 (Paquette, 1978; Paquette and Rossignol, 1978). A slight decrease of the BFC may then occur at the $\mathrm{C}$ site in two-point crosses, but the values observed are at the limit of the range of variation.

The PMS always show a considerable decrease when compared with single-point crosses. This decrease is more pronounced when the interval between the two sites becomes smaller. This decrease is still greater when the aberrant $4: 4$ asci are considered alone.

The DV is usually very low (almost 1 ) in single-point crosses involving 4 (Leblon and Rossignol, 1973; Leblon, 1974; Paquette, 1978; Paquette and Rossignol, 1978). In the two-point crosses, an increase of DV occurs, which is caused by the disparity of conversion of the A (or B) site. The excess of conversions to wild-type at site $A$ results in an excess of conversions to mutant at site $\mathrm{C}$ in the $\mathrm{A}+/+\mathrm{C}$ trans crosses I, II, III or in an excess of conversions to wild-type in the $\mathrm{AC} /++$ cis cross IV. The excess of conversions to mutant at site $B$ results in an excess of conversions to mutant at site $C$ in the $\mathrm{AB} /++$ cis cross $\mathrm{V}$. The disparity of conversion at site $\mathrm{C}$ increases from 4 to 8 when the interval between the two sites decreases.

Hence, sites of type A or B strongly decrease the PMS of the C site and impose their own disparity on it. These two effects are greatest with decreasing distance between these two sites.

\section{(iv) Double site conversions}

The results corresponding to asci $a$ to $f$ (arising from a conversion involving both sites) are shown in tables 5 and 6 .

There is no change in the DV of the A (or B) sites among double site conversions (they are always close to 10 ). In contrast, the DV of the $\mathrm{C}$ site is sharply modified (table 5). The excess of conversion at the $\mathrm{C}$ site is to mutant in trans cross with an A site (crosses I to III); in cis crosses, it is to mutant with the B site (cross IV) and to wild-type with the A site (cross V).

The decrease of the PMS among conversions for the $\mathrm{C}$ site 4 is always very great compared to the control cross. The decrease of the aberrant $4: 4$ is even greater. These decreases are the greatest in cross $\mathrm{I}$ (where the interval is the smallest), and are least in crosses IV and V, corresponding to the largest intervals.

Double site conversions represent between 79 and 96 per cent of the total conversions (table 6); they are most frequent when the sites are closest.

Thus, the modifications of the overall spectrum of the $\mathrm{C}$ site 4 are explained by the effect of the A (or B) sites in double site conversions. This effect is greater when the A (or B) to $\mathrm{C}$ interval is smaller, since double site conversions occur more frequently.

In table 6 , the double site conversions have been grouped in two classes. The first corresponds to the most frequent conversions, i.e. $6+2 \mathrm{~m}$ for the A site and $2+6 \mathrm{~m}$ for the B site. It is called a "major class". The second 


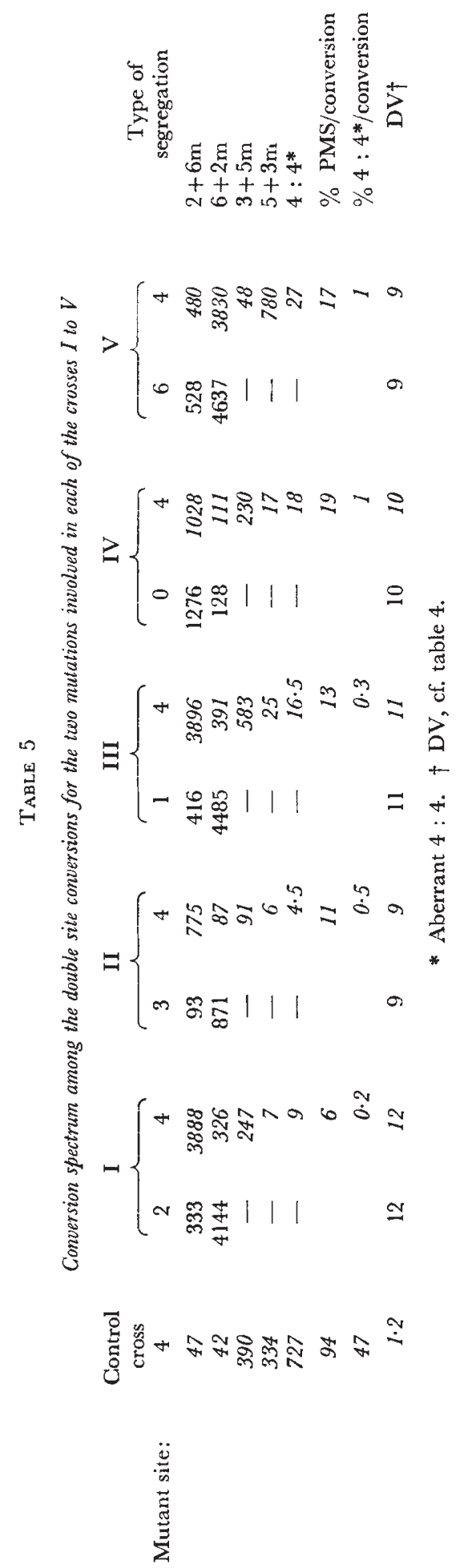


TABLE 6

Distribution of double site conversions among major and minor classes

Major class

Type of segregation

$\%$ of

double-site

conversions

Cross

I

II

III

IV

V
96

89

88

79

81

\begin{tabular}{ccc}
\multicolumn{3}{c}{$\begin{array}{c}\text { Type of segregation } \\
\text { at site } 4\end{array}$} \\
\hline $6: 2$ & $5: 3$ & ab. $4: 4$ \\
3888 & 247 & 9 \\
$93 \cdot 8 \%$ & $6 \%$ & $0 \cdot 2 \%$ \\
775 & 91 & 4.5 \\
$89 \%$ & $10 \cdot 5 \%$ & $0 \cdot 5 \%$ \\
3896 & 583 & 16.5 \\
$86 \cdot 7 \%$ & $13 \%$ & $0 \cdot 4 \%$ \\
1028 & 230 & 18 \\
$80 \cdot 6 \%$ & $18 \%$ & $1 \cdot 4 \%$ \\
3830 & 780 & 27 \\
$82 \cdot 6 \%$ & $16 \cdot 8 \%$ & $0 \cdot 6 \%$
\end{tabular}

Minor class

Type of segregation

P value*
$<0.01$
$0.05-0.10$
$<0.01$
$0.05-0.10$
$<0.01$
at site 4

\begin{tabular}{ccc}
\multicolumn{3}{c}{$\begin{array}{c}\text { Type of segregation } \\
\text { at site } 4\end{array}$} \\
\hline $6: 2$ & $5: 3$ & ab. $4: 4$ \\
326 & 7 & 0 \\
$97 \cdot 9 \%$ & $2 \cdot 1 \%$ & - \\
87 & 6 & 0 \\
$93 \cdot 5 \%$ & $6 \cdot 5 \%$ & - \\
391 & 25 & 0 \\
$94 \%$ & $6 \%$ & - \\
111 & 17 & 0 \\
$86 \cdot 7 \%$ & $13 \cdot 3 \%$ & - \\
480 & 48 & 0 \\
$90 \cdot 9 \%$ & $9 \cdot 1 \%$ & -
\end{tabular}

P value corresponds to the probabilities in the sample studied that the relative frequency of PMS $(5: 3+$ aberrant $4: 4$ ) is the same in the major and the minor class: in crosses I, III and V, the frequency of PMS is significantly lower in the minor than in the major class.

class corresponds to the least frequent conversions i.e. $2+6 \mathrm{~m}$ for the A site and $6+2 \mathrm{~m}$ for the B site. It is called a "minor class".

Within each class, three possible segregations are found for the $\mathrm{C}$ site: $6: 2,5: 3$ and aberrant $4: 4$. These three types are found in the major class of all crosses. Asci with an aberrant $4: 4$ at the $\mathrm{C}$ site, however, were not observed in the minor class. Furthermore, the proportion of asci with PMS (5:3 or aberrant $4: 4$ ) at the $\mathrm{C}$ site is lower in the minor class than in the major class. This difference is significant in crosses I, III and $\mathrm{V}$.

\section{(v) Single site conversions}

The results corresponding to asci $g$ to $k$ (corresponding to single site conversions) are shown in table 7 . The number of asci corresponding to a $6: 2$ segregation for sites 3,0 and 4 in crosses II and IV were not estimated.

TABLE 7

Conversion spectrum - among single site conversions - of the two mutations involved in each of the crosses $I$ to $V$

\begin{tabular}{|c|c|c|c|c|c|c|c|c|c|c|c|}
\hline \multirow{2}{*}{$\begin{array}{c}\text { Control } \\
\text { cross } \\
\text { Mutant site: } 4\end{array}$} & \multicolumn{2}{|c|}{ I } & \multicolumn{2}{|c|}{ II } & \multicolumn{2}{|c|}{ III } & \multicolumn{2}{|c|}{ IV } & \multicolumn{2}{|c|}{ V } & \multirow{2}{*}{$\begin{array}{c}\text { Type of } \\
\text { segregation }\end{array}$} \\
\hline & 2 & 4 & 3 & 4 & 1 & 4 & 0 & 4 & 6 & 4 & \\
\hline $\begin{array}{r}47 \\
42 \\
390 \\
334 \\
727\end{array}$ & $\begin{array}{l}10 \\
30 \\
- \\
-\end{array}$ & $\begin{array}{r}6 \\
0 \\
60 \\
172 \\
9\end{array}$ & $\begin{array}{l}\dagger \\
\pm \\
-\end{array}$ & $\begin{array}{l}\dagger \\
\dagger \\
34 \\
62 \\
3\end{array}$ & $\begin{array}{l}20 \\
57 \\
- \\
-\end{array}$ & $\begin{array}{r}19 \\
10 \\
170 \\
346 \\
25\end{array}$ & $\begin{array}{l}\dagger \\
\frac{\dagger}{-} \\
-\end{array}$ & $\begin{array}{c}\dagger \\
\dagger \\
121 \\
188 \\
28\end{array}$ & $\begin{array}{r}13 \\
9 \\
- \\
- \\
-\end{array}$ & $\begin{array}{r}32 \\
0 \\
608 \\
326 \\
59\end{array}$ & $\begin{array}{c}2+6 \mathrm{~m} \\
6+2 \mathrm{~m} \\
3+5 \mathrm{~m} \\
5+3 \mathrm{~m} \\
4: 4^{*}\end{array}$ \\
\hline 94 & - & 98 & - & - & - & 95 & - & - & - & 97 & $\%$ PMS/conversion \\
\hline 47 & - & 4 & - & - & - & 4 & - & 一 & - & 6 & $\begin{array}{l}\% 4: 4 * / \\
\text { conversion }\end{array}$ \\
\hline 1.1 & - & 2.9 & - & 1.8 & - & 2.0 & - & 1.6 & - & 1.9 & $\mathrm{DV}_{\ddagger}^{\ddagger}$ \\
\hline
\end{tabular}

* Aberrant $4: 4$. $\dagger$ The corresponding numbers were not estimated since no analysis was performed in these crosses for asci $g$ and $h$. $\ddagger$ DV: cf. table 4. 
$A$ and $B$ sites: Some $6: 2$ asci were observed for the A sites 2, 1 and 6, but the small size of the samples analysed was incompatible with any firm conclusion.

$C$ site: Some rare $6: 2$ asci were observed at the $C$ site 4 , among single site conversions, but the same remark as for $\mathrm{A}$ and $\mathrm{B}$ sites applies here.

When compared to the control cross $4 x+$, the percentage of PMS among single site conversions is not reduced in contrast to the observation for double site conversions; however, this lack of reduction applies only to $5: 3$, since the frequency of aberrant $4: 4$ is in fact drastically reduced.

A consistent change in DV is observed. This value is about 1 in the control cross and in other $4 \times+$ crosses (loc. cit.); it varies between 1.6 and 3 for single site conversions of 4 in the two-point crosses. The excess is significant in all crosses. The most frequent class of $5: 3$ among single site conversions always corresponds to the least frequent class of $5: 3$ among double site conversions. Each time the $3+5 \mathrm{~m}$ are more frequent than the $5+3 \mathrm{~m}$ among double site conversions (crosses I, II, III, IV), they are less frequent among single site conversions; on the contrary, in cross $\mathrm{V}$ where $3+5 \mathrm{~m}$ are less frequent than $5+3 \mathrm{~m}$ among double site conversions, they are more frequent among single site conversions.

This disparity among $5: 3$ in single site conversions was not observed by Leblon and Rossignol (1973) in a cross identical to cross IV. In their experiment, the $i$ asci did not appear more frequent than $j$. The explanation for this discrepancy is probably that the temperature was higher in their experiments. This rendered the pink spores very pale and sometimes difficult to distinguish from white spores. In such conditions some asci from category $i$ could have been missed and classified as parental asci having 4 brown : 4 pink spores.

\section{Discussion}

The present study confirms the results observed by Leblon and Rossignol (1973). The presence of the A (or B) mutation leads to a drastic change of the conversion spectrum of the $\mathbf{C}$ mutant: a decrease of the PMS and an appearance of a disparity in the direction of conversion. This effect is primarily due to the double site conversions ( 79 to 96 per cent as a function of the cross).

\section{(i) The origin of double site conversions}

In 80 to 98 per cent of the double site conversions (depending on the cross), both sites exhibit a $6: 2$. A much smaller fraction of the double site conversions corresponds to a $6: 2$ at the $\mathrm{A}$ (or B) site, associated either with a $5: 3$ or with an aberrant $4: 4$ at site $C$. The characteristics of the double site conversions can be explained by the interpretation of Leblon and Rossignol (1973) (fig. 2):

1. They arise from the formation of HDNA which includes the two sites.

2. The HDNA simultaneously involves two homologous chromatids.

3. The $6: 2$ ratio at the $\mathrm{A}$ (or $\mathrm{B}$ ) site results from an excision repair mechanism induced by the mismatch at this site resulting from HDNA formation. This excision repair, which restores the homozygosity of the 


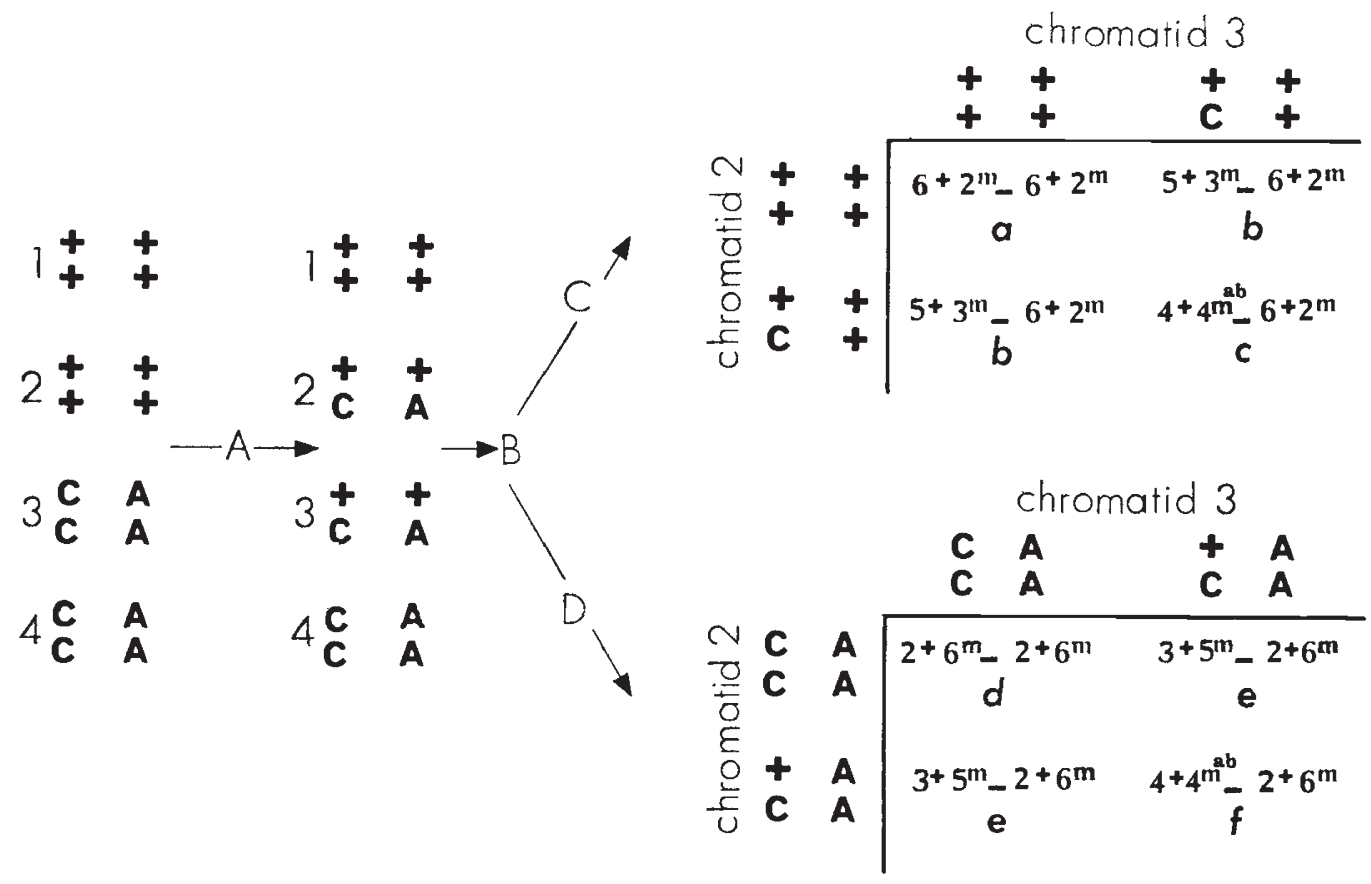

FIG. 2.- Origin of the double site conversion in the hypothesis of HDNA including both sites in two homologous chromatids, followed by a correction starting at site A. Cross V is exemplified here as in figs. 4 and 6 . A: HDNA formation. B: Correction starting at site $\mathrm{A}$ on both chromatids. G: The corrections involve the mutant strands and lead to wild-type chromatids for site A. D: The corrections involve the wild-type strands and lead to mutant chromatids for site A. The resulting segregations at each site are indicated, with the letter symbolising the type of ascus obtained (cf. fig. l).

two complementary strands, proceeds in the same direction (wild-type or mutant) in the two hybrid chromatids.

4. Excision repair does not involve only one site. It involves a segment of DNA and thus has the possibility of including the neighbouring $\mathrm{G}$ site. According to whether the overlapping occurs on both chromatids, on only one or on none, one obtains-associated with a $6: 2$ at site A (or B)-a $6: 2$, a $5: 3$ or an aberrant $4: 4$ at site $\mathrm{C}$.

The probability per chromatid that the excision repair initiated at the A (or B) site overlaps the $\mathrm{G}$ site (this will be called "co-correction") can be calculated. The $\mathrm{X}$ values given in table 8 correspond to the frequency of co-correction in each of the five crosses, for the "major correction". "Major correction" is that correction which leads to the most frequent class of conversion, i.e. wild-type (leading to $6+2 \mathrm{~m}$ asci) for the A mutations and mutant (leading to $2+6 \mathrm{~m}$ asci) for the $\mathrm{B}$ mutation. The expected number of each type of ascus can be calculated from the $X$ value and is indicated in the table beneath the observed number. The chi-square tests support the hypothesis. Consideration of the $\mathrm{X}$ values shows that the frequency of correction increases from 0.895 to 0.968 when the length of the interval between the sites decreases.

The $\mathrm{Y}$ values correspond to the frequency of co-correction for the 
占意

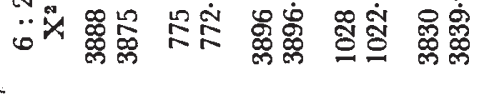


"minor correction", which is the correction leading to the least frequent class of conversion (to mutant for the A mutations and to wild-type for the B mutation). The expected number of each type of ascus is indicated in table 8 below the observed number: the absence of aberrant $4: 4$ is not surprising according to this hypothesis. The expected numbers of aberrant 4: 4 are nevertheless too small to permit statistical tests to be performed.

Within each cross, the probability of including the $\mathrm{G}$ site is always larger for the minor correction (Y) than for the major correction (X). The frequency of PMS for $\mathrm{C}$ among double site conversions has been shown to be statistically lower in the minor class than in the major class (see results): the discrepancy between the $\mathrm{X}$ and $\mathrm{Y}$ values does not result from sample fluctuations, but reflects a real difference.

The significance of this discrepancy will be discussed below.

\section{(ii) The origin of the single site conversions}

Among single site conversions, no significant change in the conversion spectrum of the $\mathrm{C}$ mutation 4 was observed by Leblon and Rossignol (1973) in a cross identical to cross IV. This observation led them to the conclusion that single site conversions resulted from the termination of HDNA between the two sites. When site $\mathrm{C}$ is involved in HDNA, it would not be influenced by site A (or B), since the latter would remain in the homoduplex state and thus could not trigger the correction process.

The present results disagree with this interpretation for the following two reasons:

1. Aberrant 4: 4 can now be detected in control crosses $4 x+$. The frequency of these aberrant $4: 4$ 's among conversions at 4 is very high (almost 0.5). This is not observed in crosses $\mathrm{I}$ to $\mathrm{V}$, where the aberrant $4: 4$ never exceed 6 per cent of single site conversions (cf. table 7).

2. In single-point crosses involving site 4, the numbers of the two types of $5: 3$ are always close to parity. This is not observed in crosses I to V, where the ratios of $5+3 \mathrm{~m}$ to $3+5 \mathrm{~m}$ (or the reverse ratios) range from $1 \cdot 6$ to almost 3. Moreover, the most frequent type of $5: 3$ among the single site conversions always corresponds to the least frequent type among double site conversions (fig. 3). In other words, the direction of the disparity depends on the A or B type of conversion spectrum of the neighbouring mutation and on its cis or trans location with respect to the $\mathrm{C}$ mutation.

HDNA terminating in the interval between the two sites does not account in any simple way for the diminution of aberrant $4: 4$ and the disparity
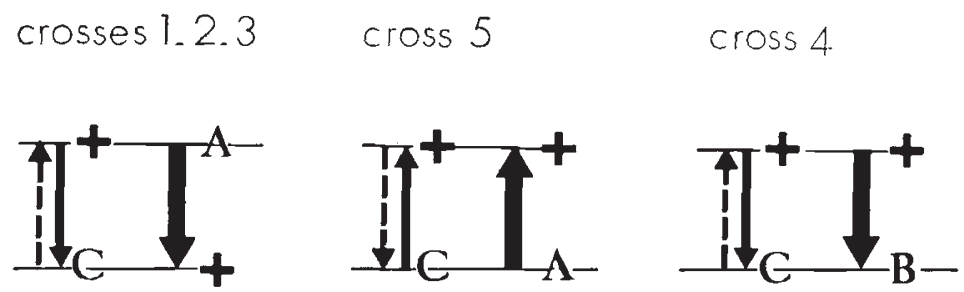

Fig. 3.-Preferential direction of conversion for site A (or B): D; and for site C in double site conversion: $\longrightarrow$; and in single site conversion: $\boldsymbol{\longrightarrow} \longrightarrow$. $40 / 3-F$ 
among $5: 3$. These results are better explained if the single site conversions at $\mathrm{G}$ result from HDNA involving both sites on two homologous chromatids. The correction at the A (or B) site then occurs in opposite directions on the two chromatids; one is corrected to wild-type, the other to mutant (fig. 4). A $4: 4$ segregation is hence recovered at the A (or B) site. When the co-correction occurs on both chromatids, no conversion is detected; a parental ascus is obtained. A $5: 3$ ascus is obtained when the co-correction occurs on only one chromatid and an aberrant $4: 4$ is obtained when excision-repair does not involve site $\mathrm{C}$ on either chromatid.

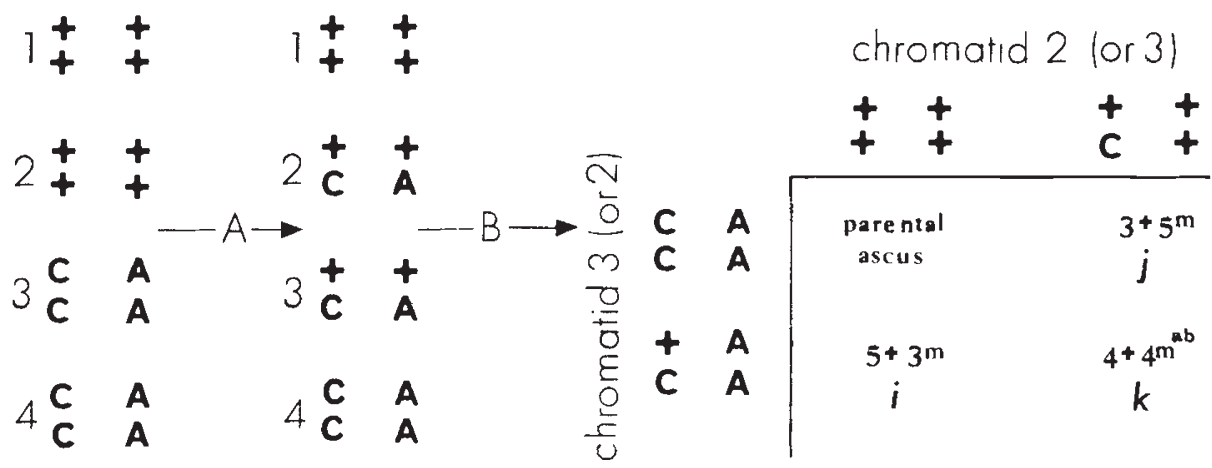

Fig. 4.-Origin of the PMS corresponding to a single site conversion at the $\mathrm{C}$ site, on the hypothesis of HDNA including both sites in two homologous chromatids, followed by a correction starting at the A site. A: HDNA formation. B: Correction starting at the A site (to mutant on one chromatid and wild-type on the other). The resulting segregations at the $\mathrm{C}$ site are indicated with the letter symbolising the type of ascus obtained (cf. Fig. 1).

According to this hypothesis, the frequencies of the three types of single site conversions corresponding to a PMS for the $\mathrm{G}$ site can be calculated by using the $\mathrm{X}$ and $\mathrm{Y}$ values. For instance, in cross $\mathrm{V}$, a $3+5 \mathrm{~m}$ segregation results from a minor co-correction on one chromatid ( $Y$ ) associated with a major correction that does not involve $\mathrm{G}$ on the other $(1-\mathrm{X})$; its probability is then $(1-\mathrm{X}) \mathrm{Y}$, in the cases where the correction of $\mathrm{A}$ occurs in opposite directions on both homologous chromatids. Similarly, the probability of a $5+3 \mathrm{~m}$ is $(1-\mathrm{Y}) \mathrm{X}$ and that of an aberrant $4: 4$ is $(1-\mathrm{X})(1-\mathrm{Y})$.

The expected frequencies of $3+5 \mathrm{~m}, 5+3 \mathrm{~m}$ and aberrant $4: 4$ among single site conversions at the $\mathrm{G}$ site corresponding to a PMS are given in table 9, below the observed frequencies. There is a good agreement between observed and expected, especially if one takes into account the error of the estimation of $\mathrm{X}$ and $\mathrm{Y}$ which is added to the sampling error. According to this hypothesis, the decreased frequency of aberrant $4: 4$ asci is explained by the very low probability that excision repair does not include the $\mathrm{G}$ site on either chromatid. The disparity is a consequence of the greater value of $\mathrm{Y}$ than of $\mathrm{X}$, which leads to the inequality:

$$
\mathrm{Y}(1-\mathrm{X})>\mathrm{X}(1-\mathrm{Y})
$$

It was stressed in Results and in fig. 3 that the second site had a consistent effect on DV at the $\mathrm{G}$ site, when $5: 3$ ratios are considered in single site conversions; this effect is the converse of that observed in double site con- 
versions. In the hypothesis, all the $5: 3$ ratios at the $\mathrm{C}$ site (in single and double site conversion) result from correction on both chromatids, with only one correction overlapping C. The category of $5: 3$ (whether $5+3 \mathrm{~m}$ or $3+5 \mathrm{~m}$ ) depends only on which correction (major or minor) overlaps $\mathrm{C}$. When the other site segregates $4: 4$ (single site conversions), the most

\section{TABLE 9}

Observed number (a); observed $(b)$ and expected* (c) fraction of $5: 3$ and aberrant $4: 4$ for site 4 , among single site PMS. Expected values are derived from the hypothesis of HDNA involving two homologous chromatids, followed by independent corrections starting at site $A$ (or B)

\begin{tabular}{ccccccc} 
& & & \multicolumn{3}{c}{$\begin{array}{c}\text { Relative frequency among } \\
\text { single site PMS }\end{array}$} \\
Cross & X & Y & & $\overbrace{3+5 m}$ & $5+3 \mathrm{~m}$ & ab. $4: 4$ \\
I & 0.968 & 0.989 & a & 60 & 172 & 9 \\
& & & b & 0.25 & 0.71 & 0.04 \\
& & & c & 0.25 & 0.74 & 0.01 \\
II & 0.943 & 0.968 & a & 34 & 62 & 3 \\
& & & b & 0.34 & 0.63 & 0.03 \\
& & & c & 0.35 & 0.63 & 0.02 \\
III & 0.931 & 0.970 & a & 170 & 346 & 25 \\
& & & b & 0.31 & 0.64 & 0.05 \\
& & & c & 0.29 & 0.69 & 0.02 \\
IV & 0.895 & 0.934 & a & 121 & 188 & 28 \\
& & & b & 0.36 & 0.56 & 0.08 \\
& & & c & 0.36 & 0.59 & 0.04 \\
V & 0.910 & 0.954 & a & 608 & 326 & 59 \\
& & & b & 0.61 & 0.33 & 0.06 \\
& & & c & 0.66 & 0.31 & 0.03
\end{tabular}

* The expected proportions were calculated from the formulae: $5+3 \mathrm{~m}=\frac{y(1-x)}{1-x y}$; $3+5 \mathrm{~m}=\frac{x(1-y)}{1-x y} ;$ ab. $4: 4=\frac{(1-x)(1-y)}{1-x y}$.

frequent class of $5: 3$ at the $\mathrm{C}$ site is determined only by the more frequent overlapping of this site by minor correction. On the contrary, when the other site segregates $6: 2$ (double site conversions), the other category of $5: 3$ is predominant since the major correction is much more frequent than the minor correction.

\section{(iii) The meaning of the difference between $X$ and $Y$ values}

It is not necessary to assume that the length of excision repair is greater in minor than in major correction in order to explain the difference between $\mathrm{X}$ and $\mathrm{Y}$ values. This difference can be explained simply by assuming that correction sometimes initiates at the $\mathrm{C}$ site (the term initiation at $\mathrm{G}$ is not meant to imply that the correction is induced by the mismatch rather than resulting from a process independent of the existence of the mutation). This hypothesis is illustrated in fig. 5.

It is clear from fig. 5 that correction initiated at $\mathrm{G}$ can contribute to co-correction ( $\mathrm{U}^{\prime}$ and $\mathrm{u}^{\prime}$ ), but cannot lead to a correction that does not 
involve $\mathrm{G}$ ( $\mathrm{V}$ or $\mathrm{v}$ ). The correction initiated at $\mathrm{G}$ is expected to occur with the same probability on either DNA strand (since the $4 \times+$ cross shows parity in the direction of conversion); consequently, its contribution to major and minor co-correction should be completely or almost equal $\left(\mathrm{U}^{\prime} \simeq \mathrm{u}^{\prime}\right)$. Since minor co-correction induced at the $\mathrm{A}$ (or $\mathrm{B}$ ) site is rarer than major correction $(u<U)$, the relative contribution of co-correction

direction
of correction initiation overlapping overlapping

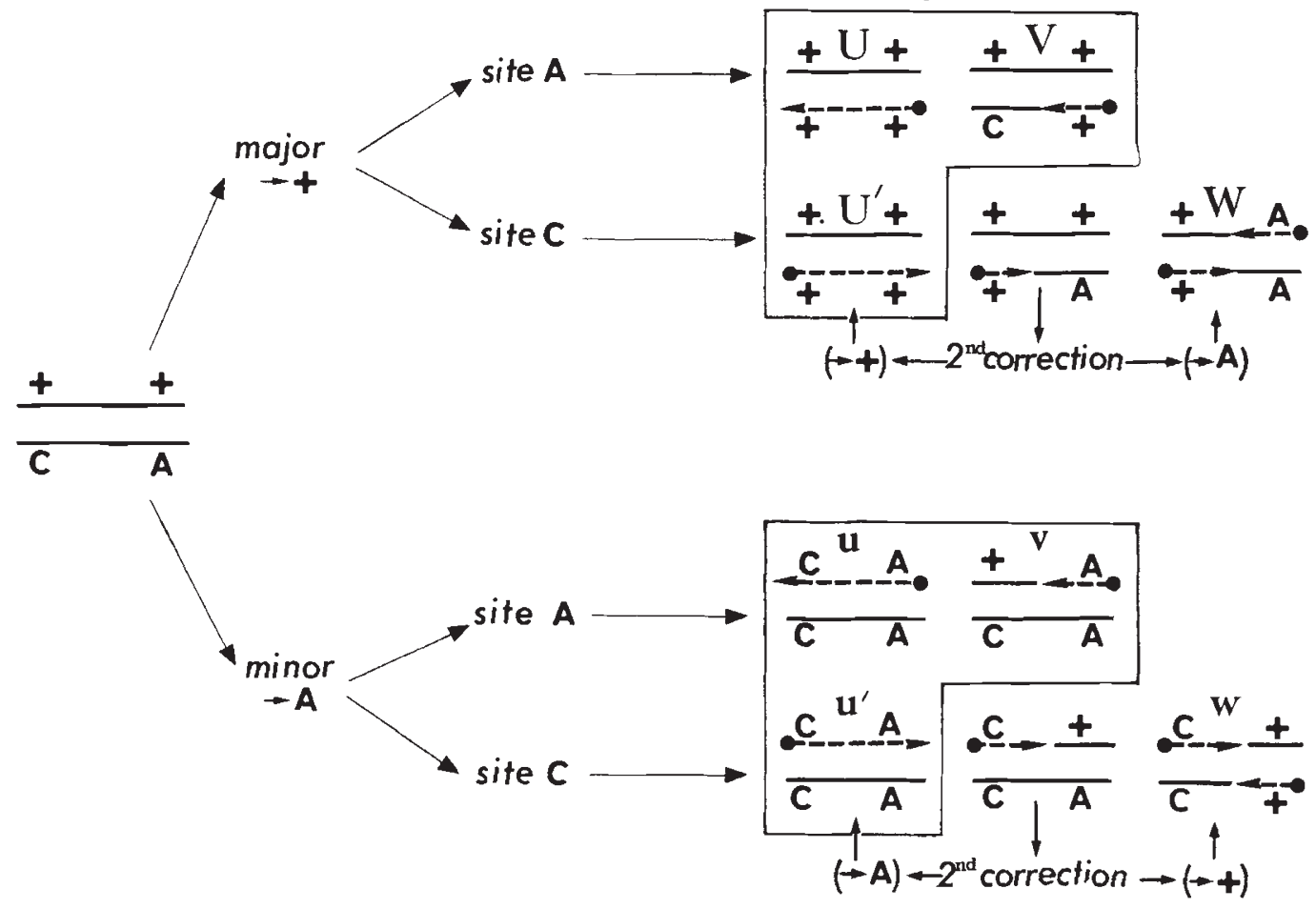

Fig. 5.-Various types of chromatids obtained after HDNA formation followed by correction in the hypothesis of a possible initiation of the correction at the $\mathrm{C}$ site.

initiated at $\mathrm{G}$ should be greater in minor than in major co-correction $\left(u^{\prime} / u+u^{\prime}>U^{\prime} / U+U^{\prime}\right)$. If the probability that correction initiated at the $\mathrm{A}$ (or $\mathrm{B}$ ) site involves $\mathrm{G}$ is the same in minor and major correction $(\mathrm{u} / \mathrm{u}+\mathrm{v}=$ $\mathrm{U} / \mathrm{U}+\mathrm{V})$, it follows that the ratio between co-correction and non-overlapping correction is greater in minor than in major correction $\left(u+u^{\prime} / v>U^{\prime}+U^{\prime} / V\right)$. This automatically leads to $\mathrm{Y}>\mathrm{X}$. Thus, the different $X$ and $Y$ values are well explained by corrections initiated at $C$ contributing relatively more to the minor than to the major correction classes. This type of initiation must not be frequent in order to give the observed results. The absence of a detectable effect of the $\mathrm{C}$ mutation in the conversion spectrum of the $\mathrm{A}$ or $\mathrm{B}$ mutations is explained by a low frequency of this event.

The hypothesis of a possible initiation of the correction at site $\mathrm{G}$ also accounts for the existence of the four types of single site $6: 2$ ratios ( $g$ and $h$ 
asci) and for the existence of the four possible events leading to asci $l$ and $m$ (fig. 6). When a correction initiated at $\mathrm{C}$ does not overlap $\mathrm{A}$ (or B), a second correction in the opposite direction at this site would lead to recombinant chromatid. If one chromatid is involved in this event, the other chromatid committed in HDNA can either undergo a co-correction or a correction that does not involve C. The first eventuality leads to the $g$ and $h$ asci : $6+2 \mathrm{~m}$ or $2+6 \mathrm{~m}$ for site $\mathrm{A}$ (or B), or $\mathrm{C}$. The second eventuality leads

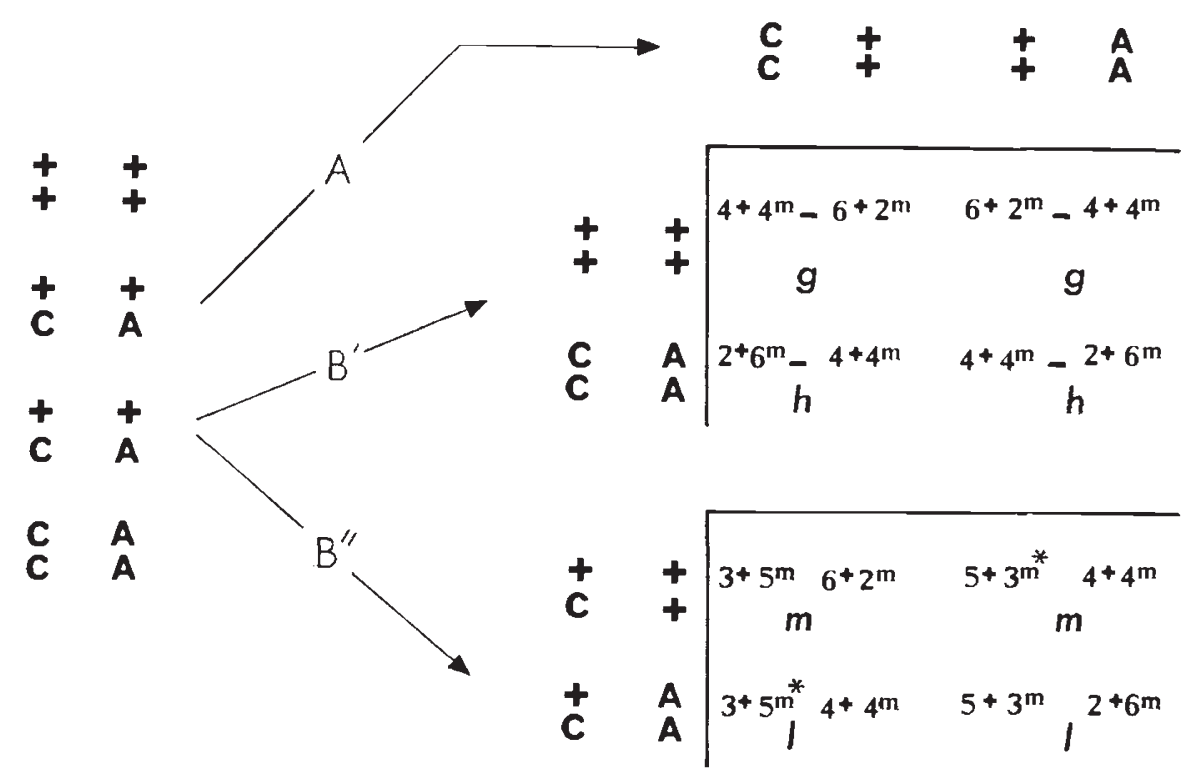

FIG. 6.-Origins of asci $g, h, l$ and $m$ in the hypothesis of HDNA including both sites in two homologous chromatids, followed by a correction initiating sometimes at the $\mathrm{C}$ site (mutant 4). A: A and C sites undergo two corrections in opposite direction (fig. 5: W and $w$ ). $B^{\prime}: A$ and $C$ sites undergo a simultaneous correction (fig. 5: $U+U^{\prime}$ and $u+u^{\prime}$ ). $B^{\prime \prime}$ : The correction involves the $A$ site but does not overlap the $G$ site (fig. 5: $\mathrm{V}$ and $\mathrm{v}$ ). The resulting segregations are indicated with the letter symbolising the type of ascus obtained.

to the four possible events corresponding to $l$ and $m$ asci. No quantitative study was performed for these events, since only a small sample of $g$ and $h$ asci was analysed and $l$ and $m$ asci (that arose in very small numbers) were not analysed. However, the only difference in the origin of $g, h$ and $l, m$ asci consists in the fact that, on one chromatid, correction spans both sites in one case $(g, h)$ whereas it does not overlap $\mathbf{C}$ in the other $(l, m)$. It can be shown from table 7 that the probability of overlapping is 10 to 100 times greater than that of non-overlapping. The ratios between $g$ and $h$ and $l$ and $m$ are fairly close from the approximation (cf. table 2).

In summary, the origin of double site conversions, single site conversions and even rarer events ( $l$ and $m$ asci), and to a good extent their relative proportions are well explained by the following hypothesis:

Almost all the conversions arise from the formation of HDNA spanning both sites on two homologous chromatids. 
Excision repair initiates primarily at the $\mathrm{A}$ (or B) site but can initiate sometimes at the $\mathrm{C}$ site.

The mean length of the excision repair tracts is greater than the intervals studied (as shown by the high frequencies of co-correction).

According to the above interpretation, the assumption that HDNA always-or almost always-involves two homologous chromatids agrees with recombination models based on a symmetrical initiation of HDNA (Holliday, 1964; Sobell, 1972; Wagner and Radman, 1975). Nevertheless, this assumption does not disagree with models assuming an asymmetrical initiation of HDNA (Meselson and Radding, 1975). Indeed a study of the conversion spectrum of various $\mathrm{C}$ type mutants in the $b 2$ gene (Paquette and Rossignol, 1978) showed that HDNA may primarily involve either only one chromatid (asymmetrical HDNA) or two chromatids (symmetrical HDNA); the region of the gene where the mutation studied is located apparently plays a preponderant role in the proportion of symmetrical and asymmetrical HDNA. In the region of 4, most HDNA is symmetrical; this could result from the distance of this site from the starting point of HDNA. The likelihood of symmetrical arising from asymmetrical HDNA through isomerisation (Meselson and Radding, loc. cit.) would in fact increase with distance from the starting point.

In the simplest version of the model advanced by Fincham and Holliday (1970) to account for map expansion, recombination in the smallest intervals may be obtained only when the heteroduplex terminates within these intervals. Inclusion of both sites in the heteroduplex would always lead to a co-correction and recombination would not occur. In the present study, the intervals are probably very small (since they allow intragenic suppression between frameshift mutations); however, the results are more easily explained if the HDNA almost always spans both sites. Recombination would then result either from a correction involving one marker only (fig. 5: V or v), leading to only one recombinant ascospore (a half-chromatid is recombined), or from corrections in opposite directions ( $W$ or $w$ ), leading to a pair of recombinant ascospores. Two remarks may be made about this situation. Firstly, the systematic spanning of sites by HDNA may be exceptional: the cluster of frameshift mutations studied here might correspond to a particular "non-stop" region for HDNA. Secondly, the variation of $\mathrm{X}$ and $\mathrm{Y}$ with distance indicates that the length of the repair tract is not a constant; however, there is no way to know the distribution of this variation since the physical distances corresponding to the intervals studied are not known. If the length of repair tracts was distributed about a mean value, map expansion is expected in the Fincham and Holliday's model, even if the HDNA always spans both sites. Data from Leblon and Paquette (1978) concerning the map of this cluster of frameshift mutants show no or little expansion when mutants with similar behaviour, i.e. $0,1,2,3,6$, are taken in consideration. This is expected if the interval considered is much smaller than the mean length of the repair tract, as is suggested by the data presented here.

Acknowledgments.-The authors wish to thank Drs J. R. S. Fincham and R. Holliday for stimulating discussions and critical reading of the manuscript.

This work was supported by grants from the "Université Paris-Sud" and from the “Laboratoire associé au C.N.R.S." n ${ }^{\circ} 86$. 


\section{REFERENCES}

FINGHAM, J. R. S., AND HOLLIDAY, R. 1970. An explanation of the structure map expansion in terms of excision repair. Mol. Gen. Genet., 109, 309-322.

Holliday, R. 1964. A mechanism for gene conversion in Fungi. Genet. Res., 5, 282-304.

LEBLON, G. 1972a. Mechanism of gene conversion in Ascobolus immersus. I. Existence of a correlation between the origin of mutants induced by different mutagens and their conversion spectrum. Molec. Gen. Genet., 115, 36-48.

LEBLon, G. 1972b. Mechanism of gene conversion in Ascobolus immersus. II. The relationship between the genetic alterations in $b 1$ or $b 2$ mutants and their conversion spectrum. Molec. Gen. Genet., 116, 322-335.

LEBlon, G. 1974. Mise en évidence et propriétés d'un mécanisme de correction mutant spécifique à l'origine de conversions chez l'Ascobolus immersus. Thèse de Doctorat ès Sciences, Université Paris-Sud, Centre d'Orsay, 217 pp.

LEBLON, G., AND PAQUETTE, N. 1978. Intragenic suppression at the $b 2$ locus in the Ascomycete Ascobolus immersus. I. Identification of three distinct clusters of suppression. Genetics (in press).

LEBlon, G., AND Rossignol, J.-L. 1973. Mechanism of gene conversion. III. The interaction of heteroalleles in the conversion process. Molec. Gen. Genet., 122, 165-182.

Lissouba, P., Mousseau, J., RIZET, G., AND Rossignol, J.-L. 1962. Fine structure of genes in Ascobolus immersus. Advanc. Genet., 11, 343-380.

Meselson, M., AND Radding, c. M. 1975. A general model for genetic recombination. Proc. Nat. Acad. Sci. U.S., 72, 358-361.

PaQueTte, N. 1978. Detection of aberrant postmeiotic $4: 4$ asci in Ascobolus immersus. Can. 7. Genet. Cytol. (in press).

PAQUetTe, N., AND Rossignol, J.-L. (1978). Gene conversion spectrum of 15 mutants giving postmeiotic segregations in the locus $b 2$ of Ascobolus immersus. Molec. Gen. Genet. (in press).

Rizet, G., ENGElman, N., LEFoRT, C., lissoubA, P., AND mousseAu, J. 1960. Sur un Ascomycète intéressant pour l'étude de certains aspects du problème de la structure du gène. C.R. Acad. Sci. (Paris), 270, 2050-2052.

SOBELl, H. M. 1972. Molecular mechanism of genetic recombination. Proc. Nat. Acad. Sci. U.S., 69, 2483-2487.

WAGNER, R. E., AND RADMAN, M. 1975. A mechanism for initiation of genetic recombination. Proc. Nat. Acad. Sci. U.S., 72, 3619-3622.

YU SUN, c. c. c. 1964. Biochemical and morphological mutants of Ascobolus immersus. Genetics, 50, 987-998. 